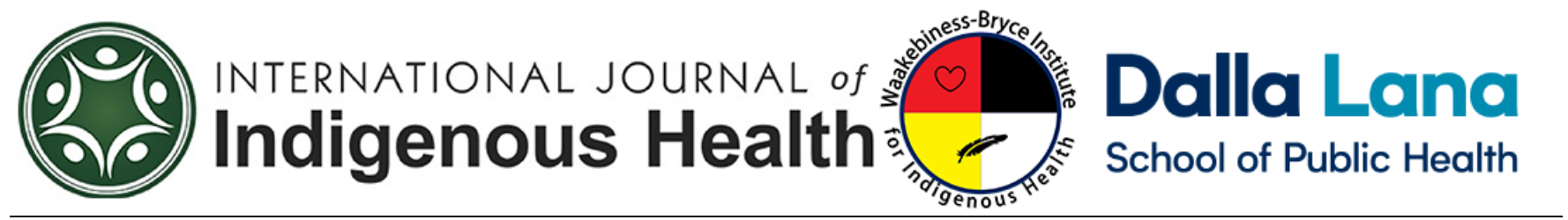

Volume 14

Issue 2. Growing Roots of Indigenous Wellbeing

Article 11

Full Issue DOI: 10.32799/ijih.v14i2.32958

October 2019

\title{
HPV Knowledge and Attitudes Among American Indian and Alaska Native Health and STEM Conference Attendees
}

\section{Naomi R. Lee, PhD,}

Department of Molecular Genetics and Microbiology, University of New Mexico, Albuquerque, NM, USA. Department of Chemistry and Biochemistry, Northern Arizona University, Flagstaff, AZ, USA naomi.lee@nau.edu

\section{Carolyn J. Noonan, MS,}

Partnerships for Native Health, Initiative for Research and Education to Advance Community Health, College of Nursing, Washington State University, Seattle, WA, USA

\section{Lonnie Nelson, PhD,}

Partnerships for Native Health, Initiative for Research and Education to Advance Community Health, College of Nursing, Washington State University, Seattle, WA, USA

\section{Jason G. Umans, MD, PhD,}

MedStar Health Research Institute, Hyattsville, MD, USA. Georgetown-Howard Universities Center for Clinical and Translational Science, Washington, DC, USA

Follow the International Journal of Indigenous Health at:

https://jps.library.utoronto.ca/index.php/ijih/index

\section{Recommended Citation}

Lee, N., Noonan, C., Nelson, L., \& Umans, J. (2019). HPV Knowledge and Attitudes Among American Indian and Alaska Native Health and STEM Conference Attendees. International Journal of Indigenous Health, 14(2), 205 - 221. DOI 10.32799/ijih.v14i2.31920 


\title{
HPV Knowledge and Attitudes Among American Indian and Alaska Native Health and STEM Conference Attendees
}

\begin{abstract}
American Indian and Alaska Native women had approximately twice the incidence of cervical cancer as white women. Preventive measures for cervical cancer rely on screening and HPV vaccination. However, vaccine series completion and catch-up vaccinations for eligible adults are low across all racial/ethnic groups. Therefore, the aim of this study was to identify gaps in knowledge and evaluate the attitudes toward HPV and the vaccine among AIANs with various levels of training in the STEM and health-related fields. A survey was used to collect data from audience members at two national conferences geared towards American Indian and Alaska Natives in health and STEM fields in September 2017. A vignette study was administered via a live electronic poll to test knowledge (true/false questions), attitudes, and to collect demographic information. Respondents self-identified as primarily American Indian and Alaska Native (74\%), pursuing or completed a graduate degree (67\%), and female $(85 \%)$. Most respondents $(86 \%)$ were aware of HPV-associated cancer in men. However, most (48-90\%) answered incorrectly to detailed true/false statements about HPV and available vaccines. After educational information was provided, opinions collected via vignettes highlighted mainly positive attitudes toward vaccination; specifically, that vaccines are safe and all eligible community members should be vaccinated (75\% and $84 \%$, respectively). We observed that our respondents with higher educational attainment still lacked accurate knowledge pertaining to HPV and the vaccine. Overall, continued education about HPV and the vaccine is needed across all levels of education including American Indian and Alaska Native community members and health professionals.
\end{abstract}

\section{Keywords}

HPV, HPV vaccine, American Indian and Alaska Native, HPV screening, vignette-based questionnaire

\section{Creative Commons License}

(c) 1 (1)

This work is licensed under a Creative Commons Attribution-Noncommercial-No Derivative Works 4.0 License. 


\section{Introduction}

Human papillomavirus (HPV) is the most common sexually transmitted infection and is the etiological agent for nearly all cervical cancer cases (Lowy \& Schiller, 2012; NCI, 2015). In 2006, the U.S. Food and Drug Administration (FDA) approved the first HPV vaccine (Gardasil ${ }^{\circledR}$ 4, Merck) that targeted four HPV genotypes: HPV-6, 11, 16, and 18 (Markowitz et al., 2007). Currently, a nonavalent vaccine, Gardasi ${ }^{\circledR}$ 9, was approved for commercial use in males and females aged 9-26 years (Petrosky et al., 2015). It protects against nine HPV genotypes; HPV-6, 11, 16, 18, 31, 33, 45, 52, and 58. Individuals who receive Gardasi ${ }^{\circledR} 9$ are protected against the HPV types that cause $90 \%$ of cervical cancers and genital warts (Joura et al., 2015).

Despite the available vaccines, approximately 4,100 women still die from cervical cancer every year. In American Indian and Alaska Native (AIAN) women, both cervical cancer incidence and death rate ratios $(\mathrm{RR}=2.11$ and 1.55 , respectively) exceed those compared to white women (Watson et al., 2014). Therefore, continued efforts are needed to estimate vaccine impact and support delivery of current and future HPV vaccines.

In the early HPV vaccine era (2006-2010), attitudes towards cervical cancer, HPV, and the vaccine were assessed in AIAN women, parents/guardians, and healthcare providers to AIANs from both rural and urban communities (Buchwald, Muller, Bell, \& Schmidt-Grimminger, 2013; Jim et al., 2012; Schmidt-Grimminger et al., 2013; Toffolon-Weiss et al., 2008). Overall, these studies showed that many participants were aware of HPV but did not connect HPV infection with the risk of cervical cancer. Barriers to vaccination include common themes such as parental role in vaccinating children, concerns about vaccine safety, age of vaccination, and fear of being in an experimental trial (Buchwald et al., 2013; Jim et al., 2012; Schmidt-Grimminger et al., 2013; Toffolon-Weiss et al., 2008). However, AIAN perceptions towards HPV and the vaccine were not assessed more recently, specifically, since the introduction of Gardasil ${ }^{\circledR} 9$.

Ours is the first vignette-based study to assess the knowledge of HPV and attitudes toward the vaccine in the current era. It also includes a unique convenience sample of highly educated AIAN health and STEM professionals and students. Finally, it utilized a modern automatic response system (ARS) shown to be effective in cancer education among AIANs (Burhansstipanov et al., 2014; Dignan, Jones, Burhansstipanov, \& Michalek, 2014). Unlike traditional surveys, the ARS, a modality used commonly in medical education, delivered immediate feedback and allowed participants to compare their responses with those of other audience members (Orr, Noonan, Whitener, \& Schwartz, 2015). Thus, our study provided continued education about HPV and HPV vaccination among professionals and students that likely serve in various health and STEM capacities across Indian country (Gampa et al., 2017; IHS, 2018; Love, Gardner, \& Legion, 1997). 


\section{Methods}

\section{Participants and Setting}

This pilot study was part of the NIH-funded Native Investigator Development (NIDP) program (grant number P30AG015292) for AIAN NIH-eligible Early Stage Investigators (Manson, Goins, \& Buchwald, 2006). The first author, Lee. was a scholar in the NIDP program during the time of data collection and analyses. Thus, we report a thorough analysis of the pilot data on HPV knowledge and attitudes from a convenient sample of primarily self-identified AIAN conference attendees.

We administered the same 45 -minute PowerPoint ${ }^{\odot}$ presentation (PowerPoint ${ }^{\odot}$ pdf file available from corresponding author) with an embedded electronic survey to assess knowledge of and attitudes about HPV and the vaccines at both the National Native Health Research Initiative (NNHRTI) conference (NNHRTI, 2018) and the American Indian Science and Engineering Society (AISES) national conference (AISES, 2018) in September 2017, both in Denver, CO. The conference organizers for NNHRTI estimated approximately 150 total attendees over the two-day conference. Meanwhile the estimated attendance at the AISES conferences was 3,000 participants. However, data collection occurred during one of seven concurrent sessions with varying topics and target audiences (AISES, 2017). The room size at AISES also limited seating capacity to 100 people. Thus, combined with NNHRTI, we estimated a maximum sample of 250 AIAN students, trainees, and professionals in the STEM and health fields.

\section{Vignette Study Description}

Briefly, three vignettes were introduced to engage the audience. Vignettes are stories generated from a range of sources including research findings, opinions of professionals in the field, and real-life case histories (Atzmuller \& Steiner, 2010; Hughes, 1998). The vignettes produced a fictional "snapshot" of certain real-life situations regarding HPV and the vaccine in tribal communities (Atzmuller \& Steiner, 2010; Orr et al., 2015). We chose narrative-style vignettes for our audience since this is consistent with the tradition of storytelling within AIAN communities and is easily incorporated in the conference settings (NIH, 2017). In addition, vignettes offer a third person perspective on sensitive topics that participants may not feel comfortable discussing such as sexually transmitted infections (Gourlay et al., 2014). In our study, the traditional survey included eight true/false questions regarding knowledge of HPV and the vaccines. Participants responded with their attitudes towards fourteen vignette-related statements using a 5-point Likert scale (strongly disagree, disagree, neither disagree nor agree, agree, and strongly agree). 
All survey responses were anonymous and collected in aggregate. Immediately after each survey question, a bar chart of the audience responses were shown on the screen via the Poll Everywhere ${ }^{\circledR}$ ARS (Miller, Ashar, \& Getz, 2003). The ARS allowed the presenter to act as a facilitator between the information and the audience. This is contrary to a traditional paper survey with limited personal interaction and typically less information provided on the survey topic (Sarvary \& Gifford, 2017; Stoneking, Grall, Min, Dreifuss, \& Spear Ellinwood, 2014; Uhari, Renko, \& Soini, 2003). Though audience members were offered the alternative of a paper survey, none elected this option.

Demographic information from each participant (age, gender identity, educational attainment, and race/ethnicity) was collected. Data on age and educational attainment were captured categorically (age: 18-26, 27-35, 36-45, 46-55, >55 years; education: high school graduate, some college, associate's degree, bachelor's degree, current graduate student, and graduate degree). Each participant could choose up to four race and ethnicity groups (white, non-Hispanic; Hispanic, Chicano/a/x, and Latino/a/x; Native American, American Indian, Alaska Native; Asian; Pacific Islander/Native Hawaiian; African or African American) or "prefer not to say." We allowed for multiple-race responses to be consistent with federal survey requirements despite limitations in data analyses (Goldstein \& Morning, 2000; Liebler \& Halpern-Manners, 2008). For example, we could not determine which respondents identified as bi- or multi-racial.

Audience participation in the study was voluntary. However, any audience member who did not participate was welcomed to attend the presentation. Inclusion criteria included age $\geq 18$ years. Informed consent was attained by agreement to survey questions. No incentives were provided to participants. This study was approved by the University of New Mexico's institutional review board (HRRC\# 17$327)$.

\section{Statistical Analysis}

Data from both conferences were pooled and descriptive statistics include percent, median, and interquartile range. Each true/false question was coded as correct or incorrect and percent correct responses were calculated for each question. Attitudes towards statements for each vignette were ascribed a value from -2 (strongly disagree) to 2 (strongly agree); a value of 0 corresponded to "neither disagree nor agree." We present the median agreement value with interquartile range and percent for each Likert scale category (Figure 1; Table 3). A median equal to 1 indicates that $50 \%$ of the sample agreed or strongly agreed with the statement; similarly, a median equal to -1 using this rating system indicates that $50 \%$ of the sample disagreed or strongly disagreed with the statement. A narrow interquartile range indicates participants were similar in their opinions about a statement. Inferential analyses were not possible because individual responses were not collected, and the sample size was limited. Median and interquartile range were computed using Stata 15.1; the figure was created using $\mathrm{R}$ 3.4.0 (Core, 2017). 


\section{Results}

The percentages of AIAN only and female respondents were the same at both conferences; $74 \%$ and $85 \%$, respectively (data not shown). In addition, the initial analyses showed similar trends in answering $\mathrm{T} / \mathrm{F}$ and vignette statements between conferences (data not shown). Most responses were collected during the NNHRTI conference (82\%) perhaps due its health-specific conference focus and more prominent feature on the agenda. Thus, results from both conferences were pooled due to similarity in demographics and responses

A summary of the pooled participants' demographic characteristics appears in Table 1. A mean value of 77 (range $=64-85$ ) audience members responded to each survey item. Most (74\%) self-reported as AIAN only or bi-/multi-racial (AIAN and other). About two-thirds reported their academic attainment as either a current graduate student or already obtained a graduate degree (MS/MPH/PhD/MD/etc.). In addition, $85 \%$ self-identified as female and $59 \%$ of the participants were aged between $18-35$ years.

Table 1. Demographic characteristics of the survey participants from two academic conferences.

\begin{tabular}{|c|c|c|}
\hline Characteristic & $\mathrm{N}$ responded & $\mathbf{N}(\%)$ \\
\hline Conference respondents* & 77 & \\
\hline National Native Health Research Initiative (NNHRTI) & & $63(82)$ \\
\hline American Indian Science and Engineering Society (AISES) & & $14(18)$ \\
\hline Race/Ethnicity** & 81 & \\
\hline American Indian or Alaska Native & & $60(74)$ \\
\hline White, non-Hispanic & & $33(41)$ \\
\hline Hispanic, Latino, Chicano & & $6(7)$ \\
\hline Asian & & $3(4)$ \\
\hline Native Hawaiian or Other Pacific Islander & & $1(91)$ \\
\hline African or African-American & & $0(0)$ \\
\hline Completed education & 77 & \\
\hline Graduate degree & & $34(44)$ \\
\hline Current graduate student & & $18(23)$ \\
\hline Bachelor's degree & & $12(16)$ \\
\hline Associate's degree & & $2(3)$ \\
\hline Some college & & $10(13)$ \\
\hline High school graduate & & $1(1)$ \\
\hline Gender & 68 & \\
\hline Female & & $58(85)$ \\
\hline Age in years & 72 & \\
\hline $18-26$ & & $19(26)$ \\
\hline $27-35$ & & $24(33)$ \\
\hline $36-45$ & & $21(29)$ \\
\hline $45-55$ & & $3(4)$ \\
\hline$>55$ & & $5(7)$ \\
\hline
\end{tabular}

* Based on average unique response to each question. ** Categories not mutually exclusive, add to $>100 \%$ 
Many of the participants were knowledgeable about HPV and its associations with cancer (Table 2). This included knowing that cervical cancer can be treated successfully (92\%) if detected early. However, most were less aware of details related to HPV and the vaccine. For example, only 10\% of respondents answered correctly to "All warts on the body are caused by HPV." In addition, 22\% of respondents correctly rejected the statement that there are (antiviral) treatment options for HPV infections. Only $29 \%$ of participants correctly rejected the statement, "The HPV vaccine protects against 9 types that can cause cancer." Finally, only 52\% correctly endorsed the statement that "The chance of contracting HPV from the HPV vaccine is zero."

Table 2. Descriptive statistics: Percentage of correct responses for True/False statements related to HPV and HPV vaccine knowledge.

\begin{tabular}{lcc}
\hline Knowledge item & $\begin{array}{c}\text { N } \\
\text { responded }\end{array}$ & N (\%) correct \\
\hline HPV knowledge: & 79 & $61(77)$ \\
HPV is the most common sexually transmitted infection (T) & 79 & $58(73)$ \\
There are over 150 types of HPV (T) & 81 & $8(10)$ \\
All warts on the body are caused by HPV (T) & 80 & $69(86)$ \\
HPV can cause cancer in men (T) & 83 & $18(22)$ \\
Some HPV infections can be effectively treated with medications (F) & & $25(29)$ \\
HPV vaccine knowledge: & 85 & $42(52)$ \\
The HPV vaccine protects against 9 HPV types that can cause cancer & 81 & \\
(F) & & $76(92)$ \\
The chance of contracting HPV from the HPV vaccine is ZERO (T) & 83 & \\
If a Pap test detects early cervical cancer, the cancer can be treated & & \\
successfully (T) & & \\
\hline
\end{tabular}

A mean value of 75 (range $=69-78)$ audience members responded to the three vignettes (Table 3). The first vignette focused on attitudes towards vaccinating children and identifying potential barriers to or influences on vaccination among young adolescents. Most participants agreed that a ten-year old female "Emma" adolescent (median = 2, 79\% agreed or strongly agreed) and male "Scott" (median =2, $82 \%$ agreed or strongly agreed) should be vaccinated (Figure 1a; Table 3). Participants had conflicting opinions about requiring the vaccine for either high school or college students. The median was 0 for both items; however, $45 \%$ disagreed while 37\% agreed regarding vaccination prior to high school. Similarly, $41 \%$ of participants disagreed while $44 \%$ agreed about requiring vaccination prior to college. Interestingly, participants generally disagreed with the notion that vaccination would lead to increased sexual activity (median $=-2,91 \%$ disagreed or strongly disagreed) or that it would imply parental approval of sexual activity (median $=-2,96 \%$ disagreed or strongly disagreed), suggesting that these were not barriers to parental consent for vaccination. 
Table 3. Median Likert agreement value with interquartile range (IQR) and raw percentage for 5-point Likert scale responses for the verbatim statements used after each vignette.

\begin{tabular}{|c|c|c|c|c|c|c|c|}
\hline Vignette item & $\begin{array}{c}\mathrm{N} \\
\text { responded }\end{array}$ & $\begin{array}{l}\text { Strongly disagree } \\
(-2) \text { N (\%) }\end{array}$ & $\begin{array}{c}\text { Disagree (-1) } \\
\quad \text { N }(\%)\end{array}$ & $\begin{array}{l}\text { Neither dis. nor } \\
\text { agr. (0) N (\%) }\end{array}$ & $\begin{array}{l}\text { Agree (1) } \\
\text { N (\%) }\end{array}$ & $\begin{array}{l}\text { Strongly } \\
\text { agree (2) } \\
\text { N (\%) }\end{array}$ & $\begin{array}{c}\text { Md } \\
(\text { IQR) }\end{array}$ \\
\hline \multicolumn{8}{|l|}{ Vignette 1: HPV vaccination } \\
\hline I should vaccinate Emily. & 75 & $7(9)$ & $5(7)$ & $4(5)$ & $15(20)$ & $44(59)$ & $2(1,2)$ \\
\hline I should vaccinate Scott. & 76 & $3(4)$ & $5(7)$ & $5(7)$ & $14(18)$ & $49(64)$ & $2(1,2)$ \\
\hline $\begin{array}{l}\text { The HPV vaccine should be required to } \\
\text { attend high school. }\end{array}$ & 75 & $10(13)$ & $24(32)$ & $13(17)$ & $15(20)$ & $13(17)$ & $0(-1,1)$ \\
\hline $\begin{array}{l}\text { The HPV vaccine should be required to } \\
\text { attend college for eligible students. }\end{array}$ & 76 & $8(11)$ & $23(30)$ & $12(16)$ & $15(20)$ & $18(24)$ & $0(-1,1)$ \\
\hline $\begin{array}{l}\text { Vaccinating against HPV will result in more } \\
\text { sexual activity among adolescents. }\end{array}$ & 77 & $46(60)$ & $24(31)$ & $3(4)$ & $3(4)$ & $1(1)$ & $-2(-2,-1)$ \\
\hline $\begin{array}{l}\text { Vaccinating young children against HPV } \\
\text { implies parents/guardians approval of sexual } \\
\text { activity. }\end{array}$ & 76 & $59(78)$ & $14(18)$ & $1(1)$ & $2(3)$ & $0(0)$ & $-2(-2,-2)$ \\
\hline \multicolumn{8}{|l|}{ Vignette 2: HPV testing } \\
\hline $\begin{array}{l}\text { All women from the community over the age } \\
\text { of } 50 \text { should get co-tested (HPV/Pap test). }\end{array}$ & 69 & $3(4)$ & $1(1)$ & $3(4)$ & $35(51)$ & 27 (39) & $1(1,2)$ \\
\hline $\begin{array}{l}\text { All women from the community over the age } \\
\text { of } 30 \text { should get co-tested (HPV/Pap test). }\end{array}$ & 77 & $0(0)$ & $1(1)$ & $4(5)$ & $38(49)$ & $34(44)$ & $1(1,2)$ \\
\hline $\begin{array}{l}\text { How confident are you in results from an } \\
\text { HPV test that is not FDA approved?* }\end{array}$ & 78 & $3(4)$ & $20(26)$ & $29(37)$ & $24(31)$ & $2(3)$ & $0(-1,1)$ \\
\hline \multicolumn{8}{|l|}{ Vignette 3: Vaccine safety } \\
\hline $\begin{array}{l}\text { HPV vaccines are safe to use within the } \\
\text { tribal community. }\end{array}$ & 72 & $4(6)$ & $3(4)$ & $11(15)$ & $34(47)$ & $20(28)$ & $1(0.25,2)$ \\
\hline $\begin{array}{l}\text { All eligible community members (male and } \\
\text { females 9-26 years) should get vaccinated. }\end{array}$ & 75 & $2(3)$ & $3(4)$ & $7(9)$ & $26(35)$ & $37(49)$ & $1(1,2)$ \\
\hline $\begin{array}{l}\text { The tribal community should vaccinate with } \\
\text { Gardasil } 9 \text { even if it costs more. }\end{array}$ & 74 & $3(5)$ & $1(2)$ & $6(9)$ & $15(23)$ & $39(61)$ & $2(1,2)$ \\
\hline $\begin{array}{l}\text { Eligible individuals should get re-vaccinated } \\
\text { with Gardasil } 9 .\end{array}$ & 74 & $3(4)$ & $2(3)$ & $22(30)$ & $37(50)$ & $10(14)$ & $1(0,1)$ \\
\hline $\begin{array}{l}\text { AIAN communities should be included in } \\
\text { future HPV vaccine clinical trials. }\end{array}$ & 76 & $3(4)$ & $1(1)$ & $2(3)$ & $23(30)$ & $47(62)$ & $2(1,2)$ \\
\hline
\end{tabular}

future HPV vaccine clinical trials.

* Response options are Strongly unconfident, Unconfident, Neither unconfident or confident, Confident, Strongly confident (in place of Strongly disagree, Disagree, Neither, Agree, Strongly agree, respectively) 
A) Attitudes towards HPV vaccination among AlAN adolescents

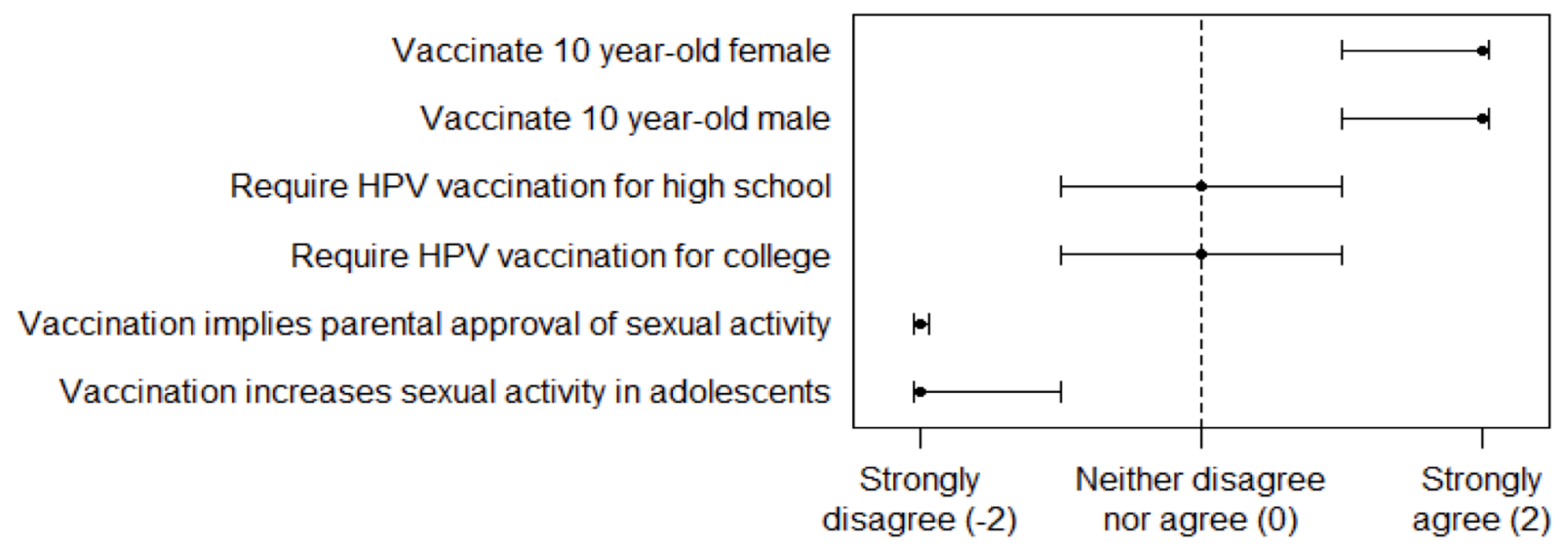

B) Attitudes towards HPV testing in men and women

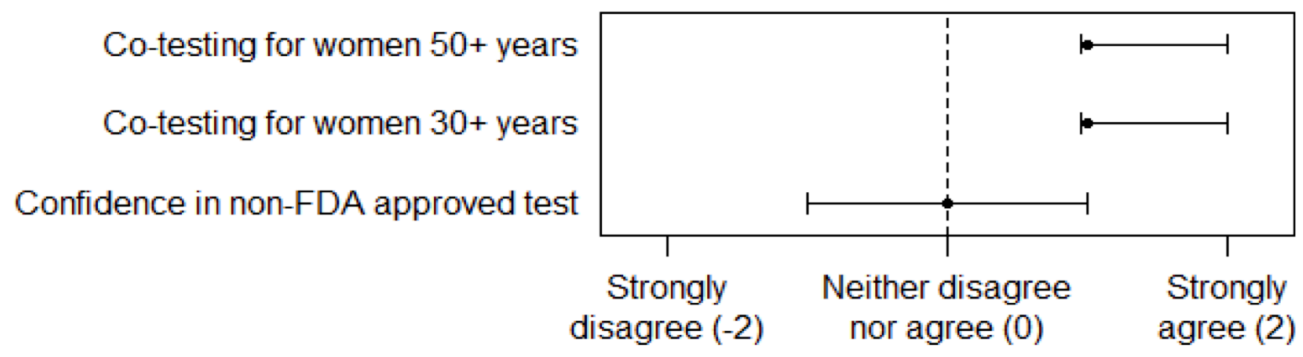

C) Attitudes towards vaccine safety, access, and inclusion in future vaccine trials

HPV vaccines are safe to use within the tribal community

Vaccinate all eligible community members

Vaccinate with Gardasil 9 even if it costs more

Eligible individuals should get re-vaccinated with Gardasil 9

Include AIAN communities in future HPV vaccine trials

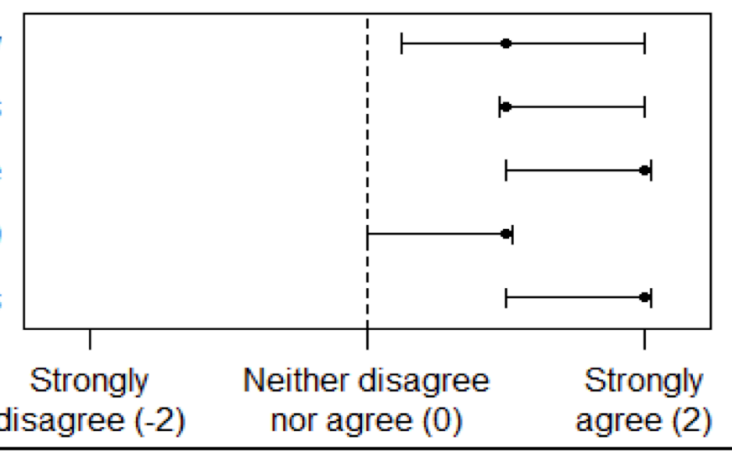

Figure 1. Median agreement value with interquartile range for 5-point Likert scale responses to the statements following the three vignettes.

The second vignette highlighted the need for cervical cancer screening and HPV co-testing in AIAN elder females along with the lack of available FDA approved testing methods for men (Figure 1b; Table 3). We saw agreement that women over the age of 50 years should be co-tested (median $=1,90 \%$ 
agreed or strongly agreed) with an equivalent endorsement for women over 30 years (median $=1,93 \%$ agreed or strongly agreed). However, participants were undecided regarding confidence in results from non-FDA approved HPV tests (median = 0, 30\% strongly disagreed or disagreed, 37\% neutral, 34\% agreed or strongly agreed).

Finally, the third vignette focused on attitudes toward the vaccines (Figure 1c; Table 3). Most respondents agreed the HPV vaccine was safe (median $=1,75 \%$ agreed or strongly agreed) and all eligible community members should be vaccinated (median $=2,84 \%$ agreed or strongly agreed). Higher cost of the newest vaccine (Gardasil ${ }^{\circledR} 9$ ) did not deter their preference for vaccination (median $=1,84 \%$ agreed or strongly agreed). The CDC does not currently suggest re-vaccination with Gardasil ${ }^{\circledR} 9$ (Harper \& DeMars, 2017; Petrosky et al., 2015), but respondents agreed that those who did not receive the newest vaccine should be re-vaccinated (median $=1,30 \%$ neutral and $64 \%$ agreed or strongly agreed). Finally, respondents strongly agreed (median $=2,92 \%$ agreed or strongly agreed) that AIANs should be included in future vaccine clinical trials.

\section{Limitations}

The data analysis was limited to pooled sample sets rather than within-participant analyses. We specifically chose ARS settings that did not link individual-level data to responses to permit anonymous voting. This format potentially eased participants into expressing their attitudes, especially if they were concerned that they might differ from those of the majority (Sarvary \& Gifford, 2017; Uhari et al., 2003), and encouraged greater survey participation in these public settings. This study was also a pilot project that limited the number of conferences the first author was able to attend during the data collection period.

Data from 2011-2016 reported AIANs accounted for only approximately $0.4 \%$ of graduate students in the health and sciences (NSF, 2016). Our sample includes an over-representation of AIAN respondents with high education attainment and provides a unique perspective from a typically underrepresented population. Future studies with larger samples sizes and inclusion of respondents that more accurately represent the general AIAN community will be needed to verify our findings.

Another limitation are the true/false statements used in these ARS-based assessments. They may not reflect subtleties of "true knowledge" among our sample. In addition, our results cannot be compared directly with previous studies that were based on interviews or written surveys and targeted lesssophisticated HPV knowledge. However, future studies aim to utilize a similar vignette-based approach to identify gaps in knowledge and evaluate the attitudes toward HPV and the vaccine among the general AIAN community. We plan to conduct this using a web-based approach with webinars and online data collection. This approach will also increase sampling and broaden the academic experience of the 
participants. Thus, verifying our findings and more accurately representing the general AIAN community.

\section{Discussion}

Our target audience from both conferences had relatively high levels of education attainment (34\% with graduate education completed) in disciplines related to health or STEM, and respondents primarily identified as AIAN (74\%). Due to the nature of both conferences, attendees were also likely to be in a health or STEM field but were not necessarily physicians. Hence, likely due to previous health knowledge, respondents were aware of the association between HPV and cancer. Most (77\%) answered correctly to the true/false statement that "HPV is the most common sexually transmitted infection" and $86 \%$ knew that "HPV can cause cancer in men." Our findings were comparable to a previous study with IHS healthcare providers, race not reported, in which a majority also correctly answered true/false questions on HPV knowledge (Jim et al., 2012). By contrast, in a separate study among AI women from South Dakota, only $41-50 \%$ of the AI women knew that HPV is a common infection and just $16 \%$ knew that HPV can cause cancer of the penis in men (Buchwald et al., 2013). Thus, as expected given education status and subject matter expertise, participants in our study sample were more knowledgeable regarding HPV compared with community samples from South Dakota.

Public knowledge and awareness about HPV are generally low among racial/ethnic subpopulations (Lai et al., 2017). However, the expected high levels of education attainment for our sample suggested that it may be more appropriate to test the knowledge of our study population with statements that reflected more advanced knowledge of HPV and the vaccines. For example, while it is generally understood that genital warts are associated with HPV, it is less commonly understood that HPV also causes both anogenital and other subcutaneous warts. Therefore, we asked participants whether all warts (i.e., anal, genital, subcutaneous) were caused by HPV, with only $10 \%$ of participants correctly responding "yes". This limited knowledge was unsurprising, since $46 \%$ of IHS healthcare providers from a previous study were also similarly unaware of the HPV subtypes associated with genital warts and those that cause cervical cancer (Jim et al., 2012). These findings are concerning since skin-to-skin contact (including sexual intercourse) from infected areas is the main route of transmission for HPV infections (Gravitt \& Winer, 2017), and this misinformation may be transmitted to community members.

We also found that treatment options for HPV infections were not clearly understood among the respondents. The statement "Some HPV infections can be effectively treated with medications" was derived from a previous study that used "There is a cure for HPV infections" (Buchwald et al., 2013). Correct responses were low for both our study (22\%) and the previously reported AI female sample (23$35 \%$ ) (Buchwald et al., 2013). Thus, the common misconception that medical treatment options were available for HPV infections still persists. This misperception may limit a sense of urgency regarding the 
need for prevention by HPV vaccination to improve health outcomes linked with infection. The lack of therapies following HPV infection should be a focus of future educational efforts.

AIAN participants in previous studies requested more educational material on the HPV vaccine (Schmidt-Grimminger et al., 2013). Since Gardasil@ 9 is now the only commercially available vaccine, we tested knowledge on its composition and safety. Although Gardasil ${ }^{\circledR} 9$ does protect against nine HPV types, seven of these are associated with cancer, the other two cause warts. Only $29 \%$ of audience members knew that not all nine HPV types in the vaccine can cause cancer (Table 2).

Focus groups in the Northern Plains that included tribal health providers, IHS providers, and AI young adult women aged 19-26 years, identified several concerns related to vaccine adverse effects and the misperception that the vaccine, itself, could cause cervical cancer (Schmidt-Grimminger et al., 2013). Therefore, we included one item to assess knowledge of vaccine safety: "The chance of contracting HPV from the HPV vaccine is ZERO.” Approximately half of the audience members answered correctly to the statement (Table 2). Thus, our findings indicate further education is needed among health care professionals and students that serve the AIAN community on HPV vaccine composition and safety.

Age of vaccination and availability for men were other concerns among the focus groups in the Northern Plains (Schmidt-Grimminger et al., 2013). Gardasil ${ }^{\circ} 9$ is approved for both males and females aged 9-26 years. However, certain findings indicate that parents were more hesitant to vaccinate children under the age of 13 year as compared with older teens (Buchwald et al., 2013). Respondents in our study mostly agreed that both ten-year old male and female adolescents should be vaccinated (Figure 1a, Table 3). In addition to age, among IHS providers, barriers for vaccinating their patients included parental views such as negative perceptions about HPV and the possibility of increased sexual promiscuity after vaccination (Buchwald et al., 2013; Toffolon-Weiss et al., 2008). However, these were not seen as barriers in our study (Figure 1a, Table 3). Interestingly, $85 \%$ of our highly-educated scientific meetingbased sample was female, suggesting the need to engage males in future vaccination education, noting both the public health benefit as well as disparities in HPV-associated oral cancers impacting males (Sonawane et al., 2017; Viens et al., 2016).

The source and race of the individual from which AIANs receive vaccine education may influence their adherence to receiving the vaccine (Lai et al., 2017). Common sources for education include the media, print materials around the community, and AIAN female relatives (Jim et al., 2012; Schmidt-Grimminger et al., 2013). More recently, there were efforts to develop culturally relevant educational materials about HPV for AIAN communities (AASTEC, 2009; GPTEC, 2018). Previous studies showed that race of the individual may also influence medical adherence due to general mistrust of medical and pharmaceutical professionals (Buchwald et al., 2006; Toffolon-Weiss et al., 2008). In our 
study, the presenter was an AI biomedical researcher whose research focused on two fields of study; vaccine development and infectious diseases affecting AIAN communities. In addition, our study emphasized HPV and cancers in AIAN communities including recent data collected from a Great Plains tribal community. Although we do not feel race negatively influenced their responses, for many this would be the first time learning about HPV and the vaccine from an AI biomedical research professional. Therefore, their positive attitude towards vaccines and involvement in future clinical trials may have been enhanced by trust between the presenter and the audience.

\section{Conclusion/s}

Our unique population and methods for gathering data highlighted the need for continued education on HPV, the vaccine, and cervical cancer across all educational levels in AIAN communities. In particular, continued education was needed among health and STEM professionals that were likely to return to their communities as future providers or healthcare workers. Additional education about HPV and HPV vaccination may help eliminate unnecessary obstacles to HPV vaccination and ultimately reduce both cervical cancer prevalence and death rates among a population with known cervical cancer disparities. We hope these findings will help current HPV vaccine programs to better educate AIAN community members, health care providers, and policy makers. 


\section{References}

AASTEC. (2009). Cervical Cancer and American Indians in New Mexico: Know the Facts. Retrieved from http://www.aastec.net/wp-content/uploads/2016/03/CervicalCancerFactSheetFinal.pdf

AISES. (2017). National conference program. Retrieved from http://conference.aises.org/sites/default/files/2017-NC-Program.pdf

AISES. (2018). American Indian Science and Engineering Society national conference. Retrieved from http://conference.aises.org/

Atzmuller, C., \& Steiner, P. M. (2010). Experimental vignette studies in survey research. Methodology, 6(3), 128-138. doi:10.1027/1614-2241/a000014

Buchwald, D., Mendoza-Jenkins, V., Croy, C., McGough, H., Bezdek, M., \& Spicer, P. (2006). Attitudes of Urban American Indians and Alaska Natives Regarding Participation in Research. J Gen internal Med, 21(6). doi: 10.1111/j.1525-1497.2006.00449.x

Buchwald, D., Muller, C., Bell, M., \& Schmidt-Grimminger, D. (2013). Attitudes Toward HPV Vaccination Among Rural American Indian Women and Urban White Women in the Northern Plains. Health Education \& Behavior, 40(6), 704-711. doi:10.1177/1090198113477111

Burhansstipanov, L., Krebs, L. U., Dignan, M. B., Jones, K., Harjo, L. D., Watanabe-Galloway, S., . . . Isham, D. (2014). Findings from the native navigators and the Cancer Continuum (NNACC) study. J Cancer Educ, 29(3), 420-427. doi:10.1007/s13187-014-0694-y

Core, T. R. (2017). Foundation for Statistical Computing: A language and environment for statistical computing. Retrieved from https://www.R-project.org/

Dignan, M. B., Jones, K., Burhansstipanov, L., \& Michalek, A. M. (2014). Evaluation lessons learned from implementing CBPR in Native American communities. J Cancer Educ, 29(3), 412-413. doi:10.1007/s13187-014-0648-4

Gampa, V., Smith, C., Muskett, O., King, C., Sehn, H., Malone, J., . . Nelson, A. K. (2017). Cultural elements underlying the community health representative - client relationship on Navajo Nation. BMC Health Serv Res, 17(1), 19. doi:10.1186/s12913-016-1956-7

Goldstein, J. R., \& Morning, A. J. (2000). The multiple-race population of the United States: issues and estimates. Proc Natl Acad Sci U S A, 97(11), 6230-6235. doi:10.1073/pnas.100086897 
Gourlay, A., Mshana, G., Birdthistle, I., Bulugu, G., Zaba, B., \& Urassa, M. (2014). Using vignettes in qualitative research to explore barriers and facilitating factors to the uptake of prevention of mother-to-child transmission services in rural Tanzania: a critical analysis. Bmc Medical Research Methodology, 14. doi: 10.1186/1471-2288-14-21

GPTEC. (2018). National Vaccination Projects. Retrieved from https://gptec.gptchb.org/infectiousdisease/national-vaccination-project/

Gravitt, P. E., \& Winer, R. L. (2017). Natural History of HPV Infection across the Lifespan: Role of Viral Latency. Viruses, 9(10). doi:10.3390/v9100267

Harper, D. M., \& DeMars, L. R. (2017). HPV vaccines - A review of the first decade. Gynecologic Oncology, 146(1), 196-204. doi:10.1016/j.ygyno.2017.04.004

Hughes, R. (1998). Considering the vignette technique and its application to a study of drug injecting and HIV risk and safer behaviour. Sociology of Health \& Illness, 20(3), 381-400. doi:

$10.1111 / 1467-9566.00107$

IHS. (2018). Community Health Representatives Program. Retrieved from https://www.ihs.gov/ihm/pc/part-3/p3c16/

Jim, C. C., Lee, J. W. Y., Groom, A. V., Espey, D. K., Saraiya, M., Holve, S., . . Thierry, J. (2012). Human Papillomavirus Vaccination Practices Among Providers in Indian Health Service, Tribal and Urban Indian Healthcare Facilities. Journal of Womens Health, 21(4), 372-378. doi:10.1089/jwh.2011.3417

Joura, E. A., Giuliano, A. R., Iversen, O. E., Bouchard, C., Mao, C., Mehlsen, J., . . Broad Spectrum, H. P. V. V. S. (2015). A 9-valent HPV vaccine against infection and intraepithelial neoplasia in women. N Engl J Med, 372(8), 711-723. doi:10.1056/NEJMoa1405044

Lai, D., Bodson, J., Davis, F. A., Lee, D., Tavake-Pasi, F., Napia, E., . . Kepka, D. (2017). Diverse Families' Experiences with HPV Vaccine Information Sources: A Community-Based Participatory Approach. J Community Health, 42(2), 400-412. doi:10.1007/s10900-016-0269-4

Liebler, C. A., \& Halpern-Manners, A. (2008). A practical approach to using multiple-race response data: a bridging method for public-use microdata. Demography, 45(1), 143-155. doi:

10.1353/dem.2008.00

Love, M. B., Gardner, K., \& Legion, V. (1997). Community health workers: who they are and what they do. Health Educ Behav, 24(4), 510-522. doi:10.1177/109019819702400409 
Lowy, D. R., \& Schiller, J. T. (2012). Reducing HPV-associated cancer globally. Cancer Prev Res (Phila), 5(1), 18-23. doi:10.1158/1940-6207.CAPR-11-0542

Manson, S. M., Goins, R. T., \& Buchwald, D. S. (2006). The Native Investigator development program: Increasing the presence of American Indian and Alaska Native scientists in aging-related research. Journal Applied Gerontology, S25(1), 105s-130s. doi: 10.1177/0733464805282727

Markowitz, L., Dunne, E. F., Saraiya, M., Lawson, H. W., Chesson, H., \& Unger, E. R. (2007). Quadrivalent Human Papillomavirus Vaccine Recommendations of the Advisory Committee on Immunization Practices (ACIP) MMWR, 56(RR02), 1-24.

Miller, R. G., Ashar, B. H., \& Getz, K. J. (2003). Evaluation of an audience response system for the continuing education of health professionals. J Contin Educ Health Prof, 23(2), 109-115. doi:10.1002/chp.1340230208

NCI. (2015). SEER Stat Fact Sheets: Cervix Uteri Cancer. Retrieved from http://seer.cancer.gov/statfacts/html/cervix.html

NIH. (2017). Storytelling about Wellness in Tribal Communities. In.

NNHRTI. (2018). National Native Health Research Training Initiative. Retrieved from http://www.nnhrti.org/

NSF. (2016). Graduate students in science, engineering, and health in all institutions, by field, citizenship, ethnicity, and race: 2011-16. Retrieved from https://ncsesdata.nsf.gov/gradpostdoc/2016/html/GSS2016_DST_13.html

Orr, R. I., Noonan, C. J., Whitener, R., \& Schwartz, S. M. (2015). Up in smoke: A tradeoff study between Tobacco as an economic development tool or public health liability in an American Indian tribe. American Indian Culture and Research Journal, 39(3), 25-39.

Petrosky, E., Bocchini, J. A., Jr., Hariri, S., Chesson, H., Curtis, C. R., Saraiya, M., . . Prevention. (2015). Use of 9-valent human papillomavirus (HPV) vaccine: updated HPV vaccination recommendations of the advisory committee on immunization practices. MMWR Morb Mortal Wkly Rep, 64(11), 300-304.

Sarvary, M. A., \& Gifford, K. M. (2017). The Benefits of a Real-Time Web-Based Response System for Enhancing Engaged Learning in Classrooms and Public Science Events. J Undergrad Neurosci Educ, 15(2), E13-E16. 
Schmidt-Grimminger, D., Frerichs, L., Black Bird, A. E., Workman, K., Dobberpuhl, M., \& WatanabeGalloway, S. (2013). HPV knowledge, attitudes, and beliefs among Northern Plains American Indian adolescents, parents, young adults, and health professionals. J Cancer Educ, 28(2), 357-366. doi:10.1007/s13187-013-0468-y

Sonawane, K., Suk, R., Chiao, E. Y., Chhatwal, J., Qiu, P., Wilkin, T., . . Deshmukh, A. A. (2017). Oral Human Papillomavirus Infection: Differences in Prevalence Between Sexes and Concordance With Genital Human Papillomavirus Infection, NHANES 2011 to 2014. Ann Intern Med. doi: 10.7326/M17-1363

Stoneking, L. R., Grall, K. H., Min, A., Dreifuss, B., \& Spear Ellinwood, K. C. (2014). Role of an audience response system in didactic attendance and assessment. J Grad Med Educ, 6(2), 335-337. doi:10.4300/JGME-D-13-00285.1

Toffolon-Weiss, M., Hagan, K., Leston, J., Peterson, L., Provost, E., \& Hennessy, T. (2008). Alaska Native parental attitudes on cervical cancer, HPV and the HPV vaccine. Int J Circumpolar Health, 67(4), 363-373. doi: 10.3402/ijch.v67i4.18347

Uhari, M., Renko, M., \& Soini, H. (2003). Exeriences of using an interactive audience response system in lectures. BMC Medical Education, 3(12), 1-6. doi: 10.1186/1472-6920-3-12

Viens, L. J., Henley, S. J., Watson, M., Markowitz, L. E., Thomas, C. C., Thompson, T. D., . .. Saraiya, M. (2016). Human Papillomavirus-Associated Cancers - United States, 2008-2012. MMWR Morb Mortal Wkly Rep, 65(26), 661-666. doi:10.15585/mmwr.mm6526a1

Watson, M., Benard, V., Thomas, C., Brayboy, A., Paisano, R., \& Becker, T. (2014). Cervical cancer incidence and mortality disparities among American Indians and Alaska Natives, 1999-2009. Cancer Epidemiology Biomarkers \& Prevention, 23(11). doi:10.1158/1538-7755.Disp13-B55 